\title{
Simulation, design and proof-of-concept of a two-stage continuous hydrothermal flow synthesis reactor for synthesis of functionalized nano-sized inorganic composite materials
}

\author{
Zielke, Philipp; Xu, Yu; Simonsen, Søren Bredmose; Norby, Poul; Kiebach, Wolff-Ragnar
}

Published in:

Journal of Supercritical Fluids

Link to article, DOI:

10.1016/j.supflu.2016.06.008

Publication date:

2016

Document Version

Peer reviewed version

Link back to DTU Orbit

Citation (APA):

Zielke, P., Xu, Y., Simonsen, S. B., Norby, P., \& Kiebach, W-R. (2016). Simulation, design and proof-of-concept of a two-stage continuous hydrothermal flow synthesis reactor for synthesis of functionalized nano-sized inorganic composite materials. Journal of Supercritical Fluids, 117, 1-12.

https://doi.org/10.1016/j.supflu.2016.06.008

\section{General rights}

Copyright and moral rights for the publications made accessible in the public portal are retained by the authors and/or other copyright owners and it is a condition of accessing publications that users recognise and abide by the legal requirements associated with these rights.

- Users may download and print one copy of any publication from the public portal for the purpose of private study or research.

- You may not further distribute the material or use it for any profit-making activity or commercial gain

- You may freely distribute the URL identifying the publication in the public portal 
Simulation, design and proof-of-concept of a two-stage continuous hydrothermal flow synthesis reactor for synthesis of functionalized nano-sized inorganic composite materials

Philipp Zielke, ${ }^{\mathrm{a},}$, Yu Xu ${ }^{\mathrm{a}}$, Søren Bredmose Simonsen ${ }^{\mathrm{a}}$, Poul Norby ${ }^{\mathrm{a}}$ and Ragnar Kiebach ${ }^{\mathrm{a}}$

${ }^{a}$ Department of Energy Conversion and Storage, Technical University of Denmark, P.O. Box 49, DK4000 Roskilde, Denmark

* Corresponding author: Tel.: +45 40187184. Fax: +45 46775688. Email address: phzi@dtu.dk.

\begin{abstract}
Computational fluid dynamics simulations were employed to evaluate several mixer geometries for a novel two-stage continuous hydrothermal flow synthesis reactor. The addition of a second stage holds the promise of allowing the synthesis of functionalized nano-materials as for example core-shell or decorated particles. Based on the simulation results, a reactor system employing a confined jet mixer in the first and a counter-flow mixer in the second stage was designed and built. The two-stage functionality and synthesis capacity is shown on the example of single- and two-stage syntheses of pure and mixed-phase NiO and YSZ particles.
\end{abstract}

1. Keywords: supercritical water; hydrothermal; continuous synthesis; nanoparticles; reactor design, computational fluid dynamics 


\section{Introduction}

Nano sized materials with particle sizes below $100 \mathrm{~nm}$ are increasingly important of for a large number of applications including healthcare, electronics, cosmetics or energy conversion and storage. Their unique properties make these materials superior, sometimes even indispensable, in many applications, and the need to transfer results from academic research into the industrial sector is growing [1,2]. In this context, the selection of appropriate methods combining synthesis of nanomaterials with required properties as well as scalability is of paramount importance. However, traditional synthesis methods such as sol-gel, co-precipitation or pyrolysis often require expensive starting materials and can be time consuming. They often are energy intense and can involve the use of organic solvents, which is undesirable from an environmental, green chemistry point of view.

One promising development towards a more environmentally friendly synthesis processes is the use supercritical fluids such as supercritical carbon dioxide or supercritical water. In this context, the continuous hydrothermal flow synthesis (CHFS) technology [3] has recently gained attention as a method capable of producing large quantities of various nanoparticles with good controllability of size, crystallinity and composition, as shown for hydrothermal batch synthesis [4]. In a continuous process a steady inflow of precursor solutions and the supercritical medium are fed to the reactor, resulting in an outflow of the suspended product and therefore eliminating frequent heat-up- and cool-down-periods. The rapid mixing allows for an excellent control of the reaction conditions (e.g. temperature, pressure and flow rates). Employing heat recovery strategies and using water as solvent adds to the method's environmental friendliness and its commercial viability. The upscaling of the CHFS process to industrial relevant production rates has been demonstrated by Hanwha Chemical [5] and in the European FP7 project SHYMAN (www.shyman.eu). 
The fast and homogeneous mixing of the precursor solution and the supercritical water is prerequisite for the synthesis of particle ensembles with narrow size distribution. Stagnant flows and backmixing effects need to be avoided to prevent the clogging of the reactor. Therefore several mixer geometries have been developed in order to optimize the flow properties. The first reported CHFS system, described by Adschiri, et al. [3], employed a simple T-union mixer, which today is still popular [6,7] because of its simplicity. More complex geometries which promise improved mixing properties are counter-flow [8,9], confined-flow [10-12] and swirl mixers [13] as well as microfluidic systems [14].

Typically CHFS reactors only have one mixing stage. Extending the reactor design to two mixing stages, which is the content of this work and has been recently presented in the literature [15], could have several advantages: Firstly it offers the possibilities to inject capping agents to prevent agglomeration of the nano particles formed in the first stage. Secondly the second mixer could introduce a second salt solution and therefore offer the possibility of synthesizing a second material in the presence of the one formed in the first stage. The second material could not only be obtained in form of isolated nanoparticles, but also could grow as a second phase on the surface of the already existing particles (decorated particles) or even form a complete layer around the particles from the first stage (core-shell structures) [16]. Such advanced nano-structures show promising properties for several applications [17] like catalysis or energy conversion devices, e.g. solid oxide fuel/electrolysis cells, which rely on well mixed composite structures with high surface areas and/or large catalytically active areas.

In the work presented here, a two stage CHFS was designed and built. In a first step, the mixing geometries for both stages are modeled and optimized using computational fluid dynamics (CFD) simulations. Based on the results, a two stage reactor capable of operating pressures up to 30MPa, Temperatures up to $450^{\circ} \mathrm{C}$ and combined flow rates of precursor solutions and supercritical water of up 
to $250 \mathrm{ml} / \mathrm{min}$ was build. For demonstrating the virtue of the two stage reactor, several successful experiments with NiO-YSZ (12 mol\% yttria stabilized zirconia, $\mathrm{Y}_{0.22} \mathrm{Zr}_{0.78} \mathrm{O}_{2-\delta}$ ), a composite system relevant for anodes used in solid oxide fuel cells, were conducted. Recent studies on optimizing the $\mathrm{Ni} / \mathrm{YSZ}$ structures show, that size-matched and well-dispersed particles as fine as possible have a beneficial influence on the long-term performance of solid oxide cells [18]. First results show that particles sizes and structures can be tuned to a large degree and that the mixing geometries chosen based on the simulations fully keep up to expectations in real life operation.

\section{Material and Methods}

\subsection{Computational details}

The three-dimensional model of the mixers were created in Dassault Systèmes SolidWorks 2014 and meshed in ANSYS 14.5 [19]. Whenever possible the symmetry of the model was exploited by using symmetry planes in order to reduce computational time. The flow field, energy transfer and species mixing were calculated using the FLUENT module of ANSYS 14.5. The methodology was adapted from

previous reports in the literature [20-24]. The standard k- $\varepsilon$-model for turbulent flow with the standard model constants implemented into the FLUENT module was used employing standard wall functions and the standard SIMPLE pressure-velocity coupling for a steady-state solution. The inbuilt energy transfer model was used. For the numerical discretization of the governing equations, a second-order upwind scheme was used. In all cases, gravity was taken into account. The density, specific heat, thermal conductivity and viscosity of pure water as a function of the temperature at constant pressure were taken from the 1995 IAPWS formulation [25] and implemented as piece-wise linear fits in the range of 275K to $705 \mathrm{~K}$ with a constant step size of $10 \mathrm{~K}$. 
In order to study the mixing behavior the liquid entering the precursor inlet was defined as a mixture of two different species of water with identical properties, as shown by e.g. Ma, et al. [20]. For the temperature dependent self-diffusion constant a piece-wise polynomial fit (two cubic polynomial functions, one above and one below the critical temperature) of the approximation by Macedo and Liu [26] was implemented as described by Sierra-Pallares, et al. [27].

The inlet turbulence intensity was set to $10 \%$ with a length scale of the inlet's diameter. Unless stated otherwise the simulations were run at 240bar under constant pressure conditions. The temperature of the sc. water was set to $400^{\circ} \mathrm{C}$, the precursor solution to $20^{\circ} \mathrm{C}$.

\subsection{Particle synthesis and characterization}

Based on the modeling work, a two-stage continuous hydrothermal flow synthesis (CHFS) reactor was built (details see chapter 3.2) and was tested by applying it to the synthesis of $\mathrm{YSZ}\left(\mathrm{Y}_{0.16} \mathrm{Zr}_{0.84} \mathrm{O}_{2-\delta}\right)$, $\mathrm{NiO}$ single-phase nanoparticles and dual-phase mixtures of YSZ and NiO nanoparticles. A scale-up production of the dual-phase mixture was also conducted in order to test the capacity of the CHFS reactor. $\mathrm{Y}\left(\mathrm{NO}_{3}\right)_{3} \bullet 6 \mathrm{H}_{2} \mathrm{O}(99.8 \%), \mathrm{ZrO}\left(\mathrm{NO}_{3}\right)_{2} \cdot 6 \mathrm{H}_{2} \mathrm{O}(99 \%)$ and $\mathrm{Ni}\left(\mathrm{NO}_{3}\right)_{2} \bullet 6 \mathrm{H}_{2} \mathrm{O}(98.5 \%)$ from Sigma Aldrich

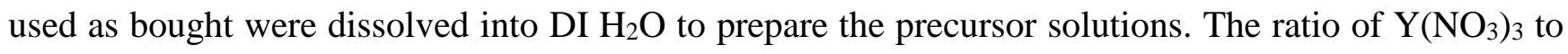
$\mathrm{ZrO}\left(\mathrm{NO}_{3}\right)_{2}$ in the solutions was determined by the stoichiometric molar ratio of YSZ. Aqueous $\mathrm{KOH}$ (Sigma Aldrich, 85\%) solution was applied as mineralizer. Details of synthesis conditions are summarized in Table 1 . The employed flowrates were $10 \mathrm{~mL} / \mathrm{min}$ for both the metal salt precursor flows and the $\mathrm{KOH}$ flow unless stated otherwise, whereas for the supercritical $\mathrm{H}_{2} \mathrm{O}$ stream, the flowrate varied from $30 \mathrm{~mL} / \mathrm{min}$ for the synthesis of single-phase particles to $35 \mathrm{~mL} / \mathrm{min}$ for the synthesis of dual-phase particles as well as the scale-up production. Unless specified otherwise, only the first stage was employed 
for the particle synthesis, and the precursor flow and the $\mathrm{KOH}$ flow were premixed before entering the first stage.

The nanoparticles were separated from the obtained slurry by a centrifuge, then washed and dried. Powder X-ray diffraction measurements were obtained from dried particles on a Bruker Robot diffractometer $(\mathrm{Cu} \mathrm{K} \alpha, 0.154 \mathrm{~nm})$ at a step size $0.01^{\circ}$. Rietveld refinement was conducted by the FullProf software suite [28] to fit the peaks, determine the unit cell parameters and quantify the compositions. By the Diffrac Eva software suite (Bruker, Germany), the crystallite size was derived from the full width at the half maximum (FWHM) of the (111) and (200) peaks in the XRD pattern of both YSZ and NiO. For TEM characterization, the nanoparticles were re-dispersed in ethanol by means of ultrasonic shaking and dropped onto a Holey carbon film/Au grid. Bright field TEM images were recorded with a JEOL 3000F microscope operating at $300 \mathrm{kV}$ with a field emission gun. Whenever quantifying the size of nanoparticles, the ImageJ software was used to outline the perimeter of the particle projection, and by assuming spherical particle shape the particle diameter was calculated. Dark-field scanning transmission electron microscopy (DF-STEM) was carried out by using the JEOL 3000F equipped with a STEM unit and a high angle annular dark field (HAADF) detector. The nominal probe size was 0.5nm and the camera length was 12cm. For composition analysis, energy dispersive X-ray spectroscopy (EDS) was carried out by using the equipped Oxford Instruments EDS detector and was processed by INCA software. Raman spectra of the dried as-prepared particles were recorded with a Renishaw inVia Reflex confocal Raman microscope. For the spectra resented in this work a 532nm laser and 50x microscope objective was employed. The spectra are averaged and background-corrected. 
Table 1. Summary of reaction conditions

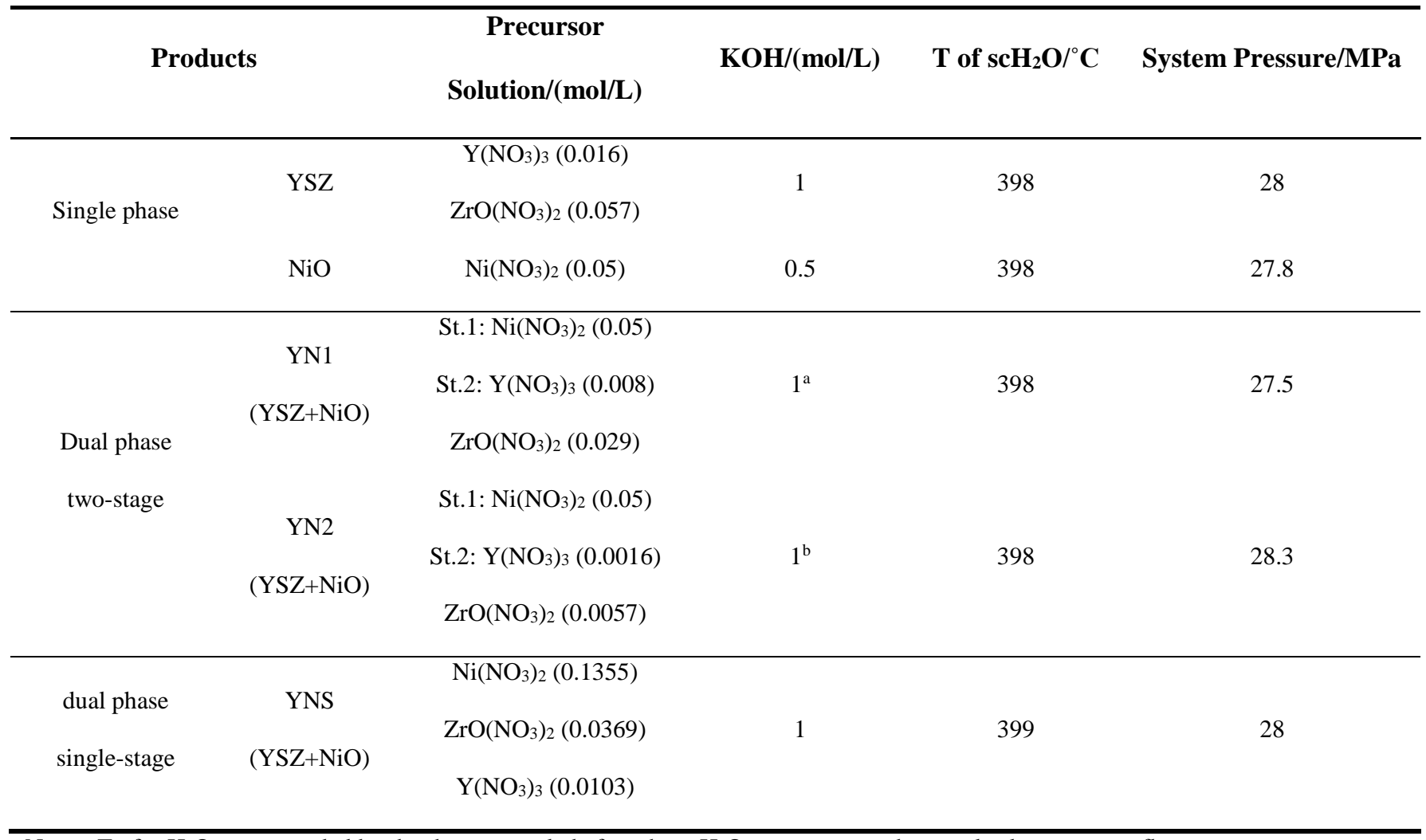

Notes: $\mathrm{T}$ of $\mathrm{scH}_{2} \mathrm{O}$ was recorded by the thermocouple before the $\mathrm{scH}_{2} \mathrm{O}$ stream meets the metal salt precursors flow; system pressure was controlled by the back pressure regulator with a variation $\pm 1 \mathrm{MPa}$; St.1 and St.2 refer to the first stage and the second stage respectively in the CHFS reactor; a, the $\mathrm{KOH}$ solution was pumped into the first stage; b, the $\mathrm{KOH}$ solution was pumped into the second stage.

\section{Results and Discussion}

\subsection{CFD modeling results}

\subsubsection{Mixing stage 1}

For the design of the first mixing stage several geometries were simulated, including various orientations of T- (introduced by Adschiri, et al. [3]), cross- and Y-junctions (both investigated by e.g. Lester, et al.[29]) as well as confined co- (after Aymonier, et al. [11] and Gruar, et al. [12]) and counter-flow 
(according to Lester, et al. [8]) geometries. With the assumed typical use-case flow rates of $20 \mathrm{ml} / \mathrm{min}$ for sc. water and precursor solution and dimensions equivalent to $1 / 4$ " tubing the simple junction geometries ( $\mathrm{T}$, cross, $\mathrm{Y}$ ) showed poor mixing properties with strong backmixing and were therefore discarded. The results of these simulations are not shown in this publication, but similar computational [27] and experimental [29-31] studies can be found in the literature. It should be mentioned though, that it has been shown that the mixing using a T-junction geometry can be greatly improved by decreasing the tube diameter [21].

For the counter- and co-flow geometries a 1/16” capillary (1.59mm O.D., 0.57mm I.D.) within a $1 / 4$ ” tube (6.35mm O.D., 3.86mm I.D.) was chosen. Because of the obvious risk of clogging the inner capillary was not suited for the precursor, but only for the sc. water stream. The meshing was done with similar element sizes to obtain comparable results (co-flow: $63 \cdot 10^{3}$ nodes, $193 \cdot 10^{3}$ elements for $165 \mathrm{~mm}^{3}$ simulated volume; counter-flow: $106 \cdot 10^{3}$ nodes, $326 \cdot 10^{3}$ elements for $353 \mathrm{~mm}^{3}$; average element size for both: $\sim 1 \cdot 10^{-3} \mathrm{~mm}^{3}$ ). The results of simulations of these two geometries are shown in Figure 1 (precursor concentration profiles). The sc. water and precursor flow rates were set to $20 \mathrm{ml} / \mathrm{min}$. The geometries were oriented vertically with both, an upward (a, b) and a downward (b, c) outflow.

The volume in which the mixing occurs was used as a semi-quantitative for the mixing efficiency. Here the mixing volume was defined as the volume in which the precursor concentration was between $5 \%$ and $45 \%$ as well as $55 \%$ to $95 \%$ of the precursor inlet concentration, in other words the volume, which contains neither the pure sc. water nor pure precursor solution nor the complete mixture of those. Given equal flow rates of the sc. water and the precursor solution and similar geometries (here $1 / 4$ ” tube) the mixing volumes are comparable and a smaller volume points towards a shorter mixing time. 
Comparing the different geometries, the co-flow showed a smaller mixing zone (upward outflow, Figure 1.a: $13.7 \mathrm{~mm}^{3}$, downward outflow, Figure 1.b: $29.3 \mathrm{~mm}^{3}$ ) than the counter-flow (downward outflow, Figure 1.c: $109.3 \mathrm{~mm}^{3}$, downward outflow, Figure 1.d: $99.9 \mathrm{~mm}^{3}$ ) and can therefore be considered more efficient. The reason for this becomes obvious when looking at the flow field shown in the upper part of Figure 2. The fast outflow from the inner capillary creates a barrel shaped vortex, which pulls the precursor stream into the sc. water. The mixing occurs almost instantly at the boundary of the vortex (see Figure 2 lower part). These findings are in agreement with results from similar simulations by Ma et al. [32].

Because of its more efficient mixing the co-flow geometry in Figure 1b was chosen for the first mixing stage and investigated further. Since the downward oriented outflow potentially prevents sedimentation of the produced particles into the inlet, it was chosen over the upward oriented geometry, although it showed a roughly twice as big mixing volume. The inherent drawback of the co-flow geometry is, that the precursor solution traveling along the outside of the inner tube (which is heated by the supercritical water stream) is prone to already start precipitating particles before reaching the mixing zone. During the course of this study, a covering of the outside of the inner tube with an oxide layer was observed, which did not lead to a block of the reactor though.

\subsubsection{Influence of flow rates}

The influence of the flow rates of the sc. water and the precursor solution on the vortex-formation in the co-flow mixer which is responsible for the excellent mixing properties was investigated. Flow rates of 5, 20 and $55 \mathrm{~mL} / \mathrm{min}$ were chosen for the simulation. These represent the minimum, assumed standard and maximum pumping rates. The values for the mixing volumes are not given, since they are not comparable due to the different flow rates. The results are summarized in Figure 3 and Table 2. 
In cases of identical precursor and sc. water flow rates, a complete mixing within the simulated volume was observed (Figure 3d). Only in the case of the lowest flow rates, a weak backmixing was evident (Figure 3a). Though the simulation still shows a sharp mixing onset and no backflow of sc. water into the precursor solution inlet, these conditions are potentially problematic in reality. A very low sc. water flow combined with higher precursor flows resulted in a very slow mixing (Figure 3b), where no complete mixing was observed in the simulated volume. The simulated flow field (not resented here) did not show the formation of a vortex (as shown in Figure 2). The outer precursor stream sheathed the sc. water stream with a persistent species gradient across the tube within the simulation volume. When combining a low precursor flow with higher sc. water flow rates strong buoyancy driven backmixing was predicted by the simulation (Figure 3e).

Given that medium to high flow rates $(20-55 \mathrm{~mL} / \mathrm{min})$ of the sc. water and the precursor solution represent typical synthesis conditions, the simulations showed that the co-flow mixer design provides complete mixing within the simulation volume without the occurrence of backmixing at all relevant flow rates (Figure 3c and 3d).

Table 2. Flow-rate-dependent mixing behavior of stage 1, the letters indicate the corresponding mixing profile in Figure 3

\begin{tabular}{cccc}
\hline \multirow{2}{*}{ Precursor flow rate / $(\mathrm{mL} / \mathrm{min})$} & \multicolumn{3}{c}{ Sc. $\mathrm{H}_{2} \mathrm{O}$ flow rate / $(\mathrm{mL} / \mathrm{min})$} \\
\cline { 2 - 4 } & weak backmixing ${ }^{\text {a) }}$ & backmixing & backmixing ${ }^{\text {e) }}$ \\
\hline 5 & slow mixing & good & good \\
20 & slow mixing $^{\text {b) }}$ & good $^{\text {c) }}$ & good $^{\text {d) }}$ \\
55 & & &
\end{tabular}




\subsubsection{Influence of geometry deviations}

Simulations of the co-flow mixer showed a strong influence of small deviations from the ideal geometry on the mixing/flow behavior. Figure 4 shows the precursor concentration profiles for a) a perfectly centered, b) $200 \mu \mathrm{m}$ eccentric and c) $400 \mu \mathrm{m}$ eccentric supercritical water inlet. The flow rates for the sc. water and the precursor solution were set to $20 \mathrm{ml} / \mathrm{min}$. The perfect concentric mixer (Figure 4a) showed an excellent mixing with a very small mixing volume and no backmixing. Upon moving the outlet of the sc. water capillary by $200 \mu \mathrm{m}$ off center (Figure $4 \mathrm{~b}$ ) the mixing profile became asymmetric with still minor backmixing without backflow to the precursor solution inlets. An eccentricity of $400 \mu \mathrm{m}$ however leads to a completely different result. The precursor concentration profile in Figure 4c shows a massive backmixing comparable to a simple cross mixer. This is suspected to be caused mainly by the buoyancy of the hot water.

It should be noted that simulations with an upside-down geometry (not presented here) showed a much smaller influence of eccentricity without backmixing, but were not take into consideration because of the anticipated top-down geometry.

\subsubsection{Mixing stage 2}

Reducing the diameter of the outflow of the first bears a high risk of clogging of the reactor. Therefore the diameter was kept (1/4" tubing, $6.35 \mathrm{~mm}$ O.D., 3.86mm I.D.) as the inner capillary of stage two. For the outside $1 / 2$ ” tubing (12.70mm O.D., 8.48mm I.D.) was chosen.

Figure 5a shows the simulated mixing behavior of the co-flow mixer under realistic conditions (40mL/min from stage $1,300^{\circ} \mathrm{C}, 20 \mathrm{~mL} / \mathrm{min}$ precursor solution, $20^{\circ} \mathrm{C}$ ). The very pronounced backmixing precludes this geometry. Only at much higher flowrates close to the maximum output of the pumps which are irrelevant for the anticipated use a satisfactory mixing behavior was observed (not shown) in the 
simulations. A counter-flow geometry with an upward outflow direction (Figure 5b) presents itself as the much more suitable choice. The relatively small capillary diameter prevents backmixing into the first stage, the buoyancy of the hot and therefore less dens mixture prevents backmixing into the precursor inlet.

\subsubsection{Influence of flow rates}

Upon varying the flow rates, no backmixing was observed in the simulations (Figure 6). It mainly influenced the position and shape of the mixing front.

\subsubsection{Influence of geometry deviations}

Figure 7 shows the eccentricity sensitivity of the counter-flow design of stage 2 . Though this geometry completely avoids any kind of backmixing upon bending the inner tube up to $500 \mu \mathrm{m}$ out of the center, an influence on the mixing efficiency is clearly visible. Figure $7 \mathrm{~b}$ shows the precursor concentration profile with an eccentricity of $250 \mu \mathrm{m}$. $3 \mathrm{~cm}$ downstream the mixing point (marked by dashed line) on the left, wider side is approx. $30 \%$ higher than on the right side. Upon $500 \mu \mathrm{m}$ eccentricity (Figure $7 \mathrm{c}$ ) the precursor concentration is $60 \%$ higher on the wider left side than on the right.

\subsection{Build-up of the CHFS based on simulation results}

A sketch of the continuous hydrothermal reactor that was built based on the results of the CFD simulations presented above is shown in Figure 9. Unless stated otherwise $1 / 4$ ” stainless steel 316 tubing (6.35mm O.D., 3.86mm I.D.) was used. The liquids are supplied by five Milroyal D metering pumps (Milton Roy, 5 - 55 mL/min capacity, internal relief valves set to 310bar). Pulsation dampeners installed downstream each pump ensure a more constant flow rate through the reactor. Pump 1 is feeding the tobe-heated medium, typically water, to the preheater. A check-valve between the preheater and pump 1 prevents a backflow of fluid and a depressurization of the system in case of a pump failure. The pressure 
at the outflow of pump 1 can be monitored by a mechanical pressure gauge and an electronical pressure transducer. The preheater consist of four aluminum plates which were machined to tightly fit approx. 6 meters of 1/4" Inconel 600 tubing (6.35mm O.D., 3.86mm I.D .) and $201 / 4$ ” heating cartridges (200W each, Watlow). The resulting total heating capacity of $4 \mathrm{~kW}$ is sufficient to heat the full output of pump 1 to supercritical conditions. The temperature of the preheater is measured by two independent thermocouples and controlled by a custom built control system (Elkas Automation). The outflow of the preheater was led past a thermocouple to measure the outflow's temperature and fed to the inner tube of the co-flow mixer as described above. Upstream the mixing stage 1 a rupture disc (Maximator, burst pressure 350bar @ $400^{\circ} \mathrm{C}$ ) was installed to depressurize the system in case of an accidental sudden pressure increase. To feed the precursor solution to mixing stage 1 (see Figure 8) two pumps ( $2 \& 3$ ) can be used. This allows for reactant mixtures that can already under normal conditions from precipitates that would harm the pumps, e.g. a mixture of $\mathrm{KOH}$ - and a metal salt solution that forms hydroxides. The streams of pump 2 und 3 are united and mixed in a simple T-junction. A check valve downstream the Tjunction prevents backflow from the reactor in case of a failure of the precursor inlet system. The outflow tube of the first mixing stage forms the inner capillary of the second stage's counter-flow mixer described in the previous section. The precursor for the second stage was fed upwards into the outer tube $(1 / 2$ ", 12.70mm O.D., 8.48mm I.D.). The precursor inlet system is identical the one used for the first stage. After mixing the upward streaming mixture is directed horizontally away from the stage 1 outlet by a Tjunction (see Figure 8) and then downwards again to avoid sedimentation. Before reaching the reheaters the temperature of the outflow of stage 2 is measured by a thermocouple. Each of the two reheaters consists of two aluminum half-cylinders which tightly fit the reactor tube on the inside and three barrel heaters (300W each, Watlow) on the outside. Together those provide a total heating capacity of $1.8 \mathrm{~kW}$. The temperature of each reheater is measured by two independent thermocouples and controlled by a 
custom built control system (Elkas Automation). Downstream the reheaters the temperature is measured before the stream is reaching a tube-in-tube heat exchanger (6m, 1/4” Inconel inner tube, Sentry Equipment Corp.). Here the product stream is cooled down to approx. $20^{\circ} \mathrm{C}$. After passing the two parallel particulate filters (Swagelok, 15 $\mu$ m pore size), the stream is depressurized to atmospheric pressure. This can either be done by a proportional relief valve (Swagelok) or a pneumatically driven back pressure regulator (Tescom, 26-1700 Series) with an active feedback control (Tescom, ER5000). Parallel to the back pressure regulator and the process relief valve a safety relief valve is installed to prevent overpressurizing the reactor in case of failure.

\subsection{Single-phase nanoparticles}

The syntheses of YSZ and NiO, which have been the subject of CHFS studies in the literature [33-35] and are well-known materials used in solid oxide fuel cells, were used to demonstrate the capabilities of the new CHFS reactor. The reaction conditions are shown in Table 1.

\subsubsection{YSZ}

Figure 10 sows the characterization results of the as-prepared YSZ particles. The XRD pattern of the obtained powder (Figure 10a) fits the one of cubic $\mathrm{Y}_{0.2} \mathrm{Zr}_{0.8} \mathrm{O}_{1.9}$. To distinguish from the monoclinic phase a Raman spectrum (Figure 10b) was recorded. The single broad feature at $\sim 610 \mathrm{~cm}^{-1}$ clearly corresponds to cubic YSZ [36]. The shape and size of the as-prepared particles are shown in the bright field TEM image (Figure 10c). The nanoparticles exhibit a relatively round shape and the result of a particle size distribution based on 141 particles is shown in Figure 10d. The mean particle size was 9.7nm with a standard deviation of 2.3nm. The crystallite size derived from the FWHM of the (111) and (220) diffraction peaks was $10 \mathrm{~nm}$ which is in good agreement with the TEM result. 
The high-resolution TEM (Figure 10e) of the as-prepared particles shows that the nanoparticles are well crystallized. Distances of the lattice spacing were measured to be $2.9 \AA$ and $1.8 \AA$, which is consistent with the (111)- and the (220)-crystal planes of cubic YSZ. The elemental composition of the obtained nanoparticles was determined by EDS and an average atomic ratio of Y:Zr in the final product was 18:82, which is close to the ratio of the starting precursor solution (22:78). According to Hayashi, et al. [33], the stoichiometric doping of $\mathrm{Y}$ into $\mathrm{ZrO}_{2}$ lattice requires a simultaneous complete conversion of both $\mathrm{Zr}$ and $\mathrm{Y}$ cations. The $\mathrm{Zr}^{4+}$ cation has a very high hydrolysis reaction rate and reaches almost complete conversion even under acidic condition. However, for a complete conversion of $\mathrm{Y}^{3+}$ cations high temperatures and $\mathrm{pH}$ values $(\mathrm{pH}>8)$ are preferable. Since these conditions were realized in the current work ( $\mathrm{T}_{\text {sc. water }} 398^{\circ} \mathrm{C}, \mathrm{T}_{\text {mixture }}$ right after stage $1 \sim 300^{\circ} \mathrm{C}, \mathrm{pH} 13$ ), the complete conversion of $\mathrm{Y}^{3+}$ and stoichiometric YSZ nanoparticles was expected.

\subsubsection{NiO}

A TEM image and a XRD pattern of the as-prepared NiO particles are presented in Figure 11. The mean size of the particles (bases on 51 particles) long side was $14.2 \mathrm{~nm}$ with a standard deviation of $4.6 \mathrm{~nm}$ (Figure 11c), the mean short side was 7.4nm with a standard deviation of $2.9 \mathrm{~nm}$ (Figure 11d). The observed Moiré pattern (see for example the marked area in Figure 11a) as well as the XRD diffractogram indicates that the particles are well crystallized. All XRD peaks can be attributed to cubic NiO. The crystallite size derived from the FWHM of the (111) and (220) XRD diffraction peaks was 13nm and is therefore in good agreement with the TEM values.

\subsection{YSZ-NiO dual-phase nanoparticles}

The successful application of only the first stage of the CHFS reactor in the separate synthesis of YSZ and $\mathrm{NiO}$ nanoparticles was extended to the two-stage synthesis of dual-phase mixtures by additionally 
applying the second stage into the synthesis process. Two examples (i.e. YN1 and YN2) are being presented in this work. In all cases, $\mathrm{Ni}\left(\mathrm{NO}_{3}\right)_{2}$ solution was pumped into the CHFS reactor at the first stage while $\mathrm{Y}\left(\mathrm{NO}_{3}\right)_{3}$ and $\mathrm{ZrO}\left(\mathrm{NO}_{3}\right)_{2}$ solutions were supplied to the second stage. For YN1 a YSZ precursor feed of $15 \mathrm{~mL} / \mathrm{min}$ was used instead of the standard $10 \mathrm{~mL} / \mathrm{min}$.

Since the pure-phase particle sizes derived from the XRD diffraction peaks and for TEM images were in good agreement, the particle sizes of the mixed phases were only calculated from the diffraction peaks.

\subsubsection{YN1}

Figure 12 shows the characterization of the as-prepared particles in the synthesis of YN1. Rietveld refinement of the powder X-ray diffraction pattern (Figure 12a) shows that the product is composed of cubic YSZ and cubic NiO. The weight fractions of $\mathrm{NiO}$ and YSZ based on the refinement are $34 \%$ and $66 \%$, which is close to the values assuming a complete conversion of the fed precursor solutions (37.35mg/min $\cong 36 \mathrm{wt} \%$ and $66.4 \mathrm{mg} / \mathrm{min} \cong 64 \mathrm{wt} \%$ for $\mathrm{NiO}$ and $\mathrm{YSZ}$ respectively). The mean crystallite sizes derived from the XRD diffraction peaks are 9nm and 16nm for YSZ (111 and 220 diffraction peak) and NiO (111 and 200 diffraction peak). Figure 12b shows a TEM overview image of the as-prepared YN1 particles. Two types of nanoparticle morphologies are oserved, a) a facetted morphology similar to the one observed for the pure $\mathrm{NiO}$ sample (Figure 11) and b) a rounded morphology similar to that of the pure YSZ (Figure 10). The particle size is in the order of 10 to $20 \mathrm{~nm}$, which is in accordance with the XRD results. It is further observed from Figure 12c, that the two types of particles are not separated, but well mixed. Measurements of lattice spacings derived from the high-resolution TEM image (Figure 12c) further show that the round particles have lattice distance consistent with cubic YSZ while the faceted ones have lattice distances consistent with cubic $\mathrm{NiO}$. 
All this strongly indicate that the rounded particles are cubic YSZ particles and the facetted particles are cubic NiO. The morphologies and sizes of the two phases in the mixture are similar to the ones from the single phase syntheses, and are very well mixed on a nano scale, which is hard to achieve by simply mixing the pure phases

\subsubsection{YN2}

Results from TEM and XRD characterization of YN2 are shown in Figure 13. Compared to YN1, where the obtained particles were homogenous in size, significant differences in the morphology and size of the obtained crystals were found. TEM characterization (Figure 13b) shows that for YN2 the NiO has a faceted shape as also observed for the pure NiO sample (figure 11) and for sample YN1 (figure 12), however the crystal size is significantly larger compared to YN1. Here NiO particles in the range of for example 80nm (long edge) $\times$ 40nm (short edge) were found, which is about five times larger compared to YN1. Additionally, two types of nano particle accumulations can be observed around the large $\mathrm{NiO}$ crystals; the first one is only rounded nanoparticles with diameters around 5nm (Figure 13b area marked c, same area at higher resolution in Figure 13c). Measurements for lattice distances from HRTEM images of these particles (Figure 13c) show consistency with cubic YSZ. Between the rounded YSZ particles, particle with an elongated plate like morphology (ca. 10nm $\times 5 \mathrm{~nm}$ ) is observed (Figure 13b area marked d, same area at higher resolution in Figure 13d). Measurements of lattice distances of these particles are consistent with $\mathrm{NiO}$ (Figure 13d). The insertion in Figure 13b is an overview image of pure $\mathrm{NiO}$ nanoparticles which were sampled before the precursor solution for 8YSZ was pumped into the CHFS reactor. Here only the larger $\mathrm{NiO}$ particles were observed. The element mapping (Figure 13f) by combing EDS and DF-STEM indicates that the main phase is NiO (distribution represented by Ni) and YSZ 
(distribution represented by $\mathrm{Zr}$ ) distributes around the NiO, supporting the TEM findings described above.

Rietveld refinement of the XRD powder diffractogram (Figure 13a) of YN2 shows that the particles are composed of the same phases found in YN1. However, for YN2 two sets of calculated Bragg reflection positions assigned to $\mathrm{NiO}$ must be used to describe the peak shape properly, i.e. two different populations of crystals with different crystallite size (and slightly different unit cell parameters, $4.1967 \AA$ and

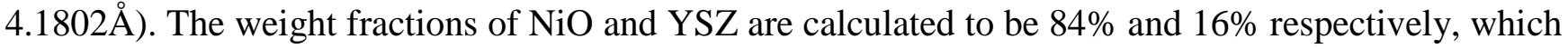
is expected due to the higher weight rate of $\mathrm{NiO}$ precursor compared to the $\mathrm{YSZ}$ precursor $(37.35 \mathrm{mg} / \mathrm{min}$ $\cong 81 \mathrm{wt} \%$ and $8.86 \mathrm{mg} / \mathrm{min} \cong 19 \mathrm{wt} \%$ for $\mathrm{NiO}$ and $\mathrm{YSZ}$ respectively, assuming full conversion).

The formation of $\mathrm{NiO}$ with such different crystal sizes in YN1 compared to YN2 can be explained by the variation of the synthesis conditions. During the synthesis of $\mathrm{YN} 2$, the $\mathrm{Ni}\left(\mathrm{NO}_{3}\right)_{2}$ solution was mixed with the $\mathrm{scH}_{2} \mathrm{O}$ stream in the first stage under neutral $\mathrm{pH}$ conditions. It is known from literature [34] that $\mathrm{NiO}$ formed under such conditions tends to be larger compared to particles synthesized at high $\mathrm{pH}$ values. At the same time the conversion rate of the of $\mathrm{Ni}^{2+}$ cations under the neutral $\mathrm{pH}$ condition is reported to be less than 70\% [34]. In conclusion, the outflow of the first stage consists of large $\mathrm{NiO}$ particles and a significant amount of unconverted $\mathrm{Ni}^{2+}$ salt solution. In the second stage the YSZ-precursor and $\mathrm{KOH}$ solution were pumped into the CHFS reactor, mixed with the outflow coming from the first stage ( $\sim 300^{\circ} \mathrm{C}$ ), and heated up to $\sim 390^{\circ} \mathrm{C}$ by the reheaters. Under these reaction conditions (high $\mathrm{pH}$ and high temperature) the agglomerations of YSZ and small NiO particles (Figure 13c) form, indicating that unconverted $\mathrm{Ni}^{2+}$ hydrolyzed and converted to $\mathrm{NiO}$ after mixing with the alkaline solution in the second stage. In conclusion, the relative positions and structure of the final product can be described as $\mathrm{NiO}$ crystals surface decorated with YSZ-NiO. 


\subsubsection{Dual-phase single-stage NiO-YSZ (YNS)}

The TEM images (a representative shown in Figure 14a) of the NiO and YSZ nanoparticles synthesized in a single stage reaction show similar sizes and morphologies to the ones from the two-stage synthesis YN1. Well crystallized particles of similar sizes around 10nm were obtained. From the measured crystal plane distances the particles were either identified as cubic NiO or YSZ. Refinement of the XRD pattern gives that the mixture is composed of $27.1 w t \%$ YSZ and $72.9 w t \% \mathrm{NiO}$ (assuming full conversion: $57.1 \mathrm{mg} / \mathrm{min} \cong 36.1 \mathrm{wt} \% \mathrm{YSZ}$ and $101.2 \mathrm{mg} / \mathrm{min} \cong 63.9 \mathrm{wt} \% \mathrm{NiO})$. The mean crystallite sizes derived from the XRD diffraction peaks are 9nm and 7nm for YSZ (111 and 220 diffraction peak) and NiO (111 and 200 diffraction peak) respectively.

Since NiO-YSZ nanocomposites are used as fuel electrode material in state-of-the-art solid oxide fuel/electrolysis cells and the CHFS synthesis route has been proven to be viable for the production of dense cermets [37], a scaled-up dual-phase single-stage production run was executed. Approx. 140g of nanoparticles were collected in $18 \mathrm{~h}$, proving that the designed synthesis capacity of the CHFS reactor can be reached.

\section{Conclusions}

Computational fluid dynamics simulations were employed to identify the most promising mixer geometries for a two-stage continuous hydrothermal flow reactor. Further simulations were carried out to evaluate the mixing behavior for changes in flow rates and geometry deviations. Based on the results a CHFS system was designed and built. After successful single-stage syntheses of YSZ and NiO the twostage capabilities were tested. In first test runs the ability to tailor the morphology of composite materials 
was proven. Lastly a scale-up of a dual-phase single-stage synthesis was performed, providing sufficient amounts of nanoparticles for prototyping of energy conversion devices.

\section{Acknowledgements}

The Authors thank Danish Council for Independent Research (DFF) for funding within the ProEco project. Moreover the authors would like to thank Henrik Fanø Clausen and Christian Kallesøe from the Danish Technological Institute and Bo Bummerstedt and Jacob Becker Iversen from the University of Aarhus fruitful discussions and support with the reactor design.

\section{References}

[1] Y. Lu, S. Ozcan, Green nanomaterials: On track for a sustainable future, Nano Today. 10 (2015) 417420. doi:10.1016/j.nantod.2015.04.010.

[2] G.R. Patzke, Y. Zhou, R. Kontic, F. Conrad, Oxide nanomaterials: Synthetic developments, mechanistic studies, and technological innovations, Angew. Chemie - Int. Ed. 50 (2011) 826-859. doi:10.1002/anie.201000235.

[3] T. Adschiri, K. Kanazawa, K. Arai, Rapid and Continuous Hydrothermal Crystallization of Metal Oxide Particles in Supercritical Water, J. Am. Ceram. Soc. 75 (1992) 1019-1022. doi:10.1111/j.11512916.1992.tb04179.x.

[4] K. Byrappa, M. Yoshimura, Hydrothermal Technology_Principles and Applications, in: Handb. Hydrothermal Technol., 2013: pp. 1-49. doi:10.1016/B978-0-12-375090-7.00001-3.

[5] T. Adschiri, Y.-W. Lee, M. Goto, S. Takami, Green materials synthesis with supercritical water, Green Chem. 13 (2011) 1380. doi:10.1039/c1gc15158d.

[6] J.J.-D. Kim, Y.-S. Park, B. Veriansyah, Y.-W. Lee, Continuous Synthesis of Surface-Modified Metal 
Oxide Nanoparticles Using Supercritical Methanol for Highly Stabilized Nanofluids, Chem. Mater. 20 (2008) 6301-6303. doi:10.1021/cm8017314.

[7] P. Hald, J. Becker, M. Bremholm, J.S. Pedersen, J. Chevallier, S.B. Iversen, et al., Supercritical Propanol-Water Synthesis and Comprehensive Size Characterisation of Highly Crystalline anatase TiO2 Nanoparticles, J. Solid State Chem. 179 (2006) 2674-2680. doi:10.1016/j.jssc.2006.05.012.

[8] E. Lester, P. Blood, J. Denyer, D. Giddings, B. Azzopardi, M. Poliakoff, Reaction engineering: The supercritical water hydrothermal synthesis of nano-particles, J. Supercrit. Fluids. 37 (2006) 209-214. doi:10.1016/j.supflu.2005.08.011.

[9] X. Weng, J.K. Cockcroft, G. Hyett, M. Vickers, P. Boldrin, C.C. Tang, et al., High-throughput continuous hydrothermal synthesis of an entire nanoceramic phase diagram., J. Comb. Chem. 11 (2009) 829-34. doi:10.1021/cc900041a.

[10] E.S. Ilin, S. Marre, V. Jubera, C. Aymonier, Continuous supercritical synthesis of high quality UVemitting ZnO nanocrystals for optochemical applications, J. Mater. Chem. C. 1 (2013) 5058. doi:10.1039/c3tc30737a.

[11] Y. Roig, S. Marre, T. Cardinal, C. Aymonier, Synthesis of Exciton Luminescent ZnO Nanocrystals Using Continuous Supercritical Microfluidics, Angew. Chemie Int. Ed. 50 (2011) 12071-12074. doi:10.1002/anie.201106201.

[12] R.I. Gruar, C.J. Tighe, J.A. Darr, Scaling-up a Confined Jet Reactor for the Continuous Hydrothermal Manufacture of Nanomaterials, Ind. Eng. Chem. Res. 52 (2013) 5270-5281. doi:10.1021/ie302567d.

[13] S. Kawasaki, K. Sue, R. Ookawara, Y. Wakashima, A. Suzuki, Development of novel micro swirl mixer for producing fine metal oxide nanoparticles by continuous supercritical hydrothermal method., J. Oleo Sci. 59 (2010) 557-562. doi:10.5650/jos.59.557.

[14] S. Marre, A. Adamo, S. Basak, C. Aymonier, K.F. Jensen, Design and Packaging of Microreactors for 
High Pressure and High Temperature Applications, Ind. Eng. Chem. Res. 49 (2010) 11310-11320. doi:10.1021/ie101346u.

[15] H.L. Hellstern, J. Becker, P. Hald, M. Bremholm, A. Mamakhel, B.B. Iversen, Development of a DualStage Continuous Flow Reactor for Hydrothermal Synthesis of Hybrid Nanoparticles, Ind. Eng. Chem. Res. (2015) 150818144017002. doi:10.1021/acs.iecr.5b02899.

[16] H.L. Hellstern, A. Mamakhel, M. Bremholm, B.B. Iversen, Core-shell nanoparticles by silica coating of metal oxides in a dual-stage hydrothermal flow reactor, Chem. Commun. (2016). doi:10.1039/C5CC09743F.

[17] R. Ghosh Chaudhuri, S. Paria, Core/shell nanoparticles: classes, properties, synthesis mechanisms, characterization, and applications., Chem. Rev. 112 (2012) 2373-433. doi:10.1021/cr100449n.

[18] A. Hauch, K. Brodersen, M. Chen, M.B. Mogensen, Ni/YSZ electrodes structures optimized for increased electrolysis performance and durability, Solid State Ionics. 293 (2016) 27-36. doi:10.1016/j.ssi.2016.06.003.

[19] ANSYS, (2012). www.ansys.com.

[20] C.Y. Ma, J.J. Liu, Y. Zhang, X.Z. Wang, Simulation for scale-up of a confined jet mixer for continuous hydrothermal flow synthesis of nanomaterials, J. Supercrit. Fluids. 98 (2015) 211-221. doi:10.1016/j.supflu.2014.12.016.

[21] S.-I. Kawasaki, K. Sue, R. Ookawara, Y. Wakashima, A. Suzuki, Y. Hakuta, et al., Engineering study of continuous supercritical hydrothermal method using a T-shaped mixer: Experimental synthesis of NiO nanoparticles and CFD simulation, J. Supercrit. Fluids. 54 (2010) 96-102. doi:10.1016/j.supflu.2010.03.001.

[22] A. Leybros, R. Piolet, M. Ariane, H. Muhr, F. Bernard, F. Demoisson, CFD simulation of ZnO nanoparticle precipitation in a supercritical water synthesis reactor, J. Supercrit. Fluids. 70 (2012) 17-26. 
doi:10.1016/j.supflu.2012.06.001.

[23] L. Zhou, S. Wang, D. Xu, Y. Guo, Impact of Mixing for the Production of CuO Nanoparticles in Supercritical Hydrothermal Synthesis, Ind. Eng. Chem. Res. 53 (2014) 481-493. doi:10.1021/ie4029413.

[24] C.Y. Ma, C.J. Tighe, R.I. Gruar, T. Mahmud, J. a. Darr, X.Z. Wang, Numerical modelling of hydrothermal fluid flow and heat transfer in a tubular heat exchanger under near critical conditions, J. Supercrit. Fluids. 57 (2011) 236-246. doi:10.1016/j.supflu.2011.03.007.

[25] W. Wagner, The IAPWS Formulation 1995 for the Thermodynamic Properties of Ordinary Water Substance for General and Scientific Use, J. Phys. Chem. Ref. Data. 31 (1999) 387. doi:10.1063/1.1461829.

[26] E.A. Macedo, H. Liu, Accurate correlations for the self-diffusion coefficients of CO2, CH4, C2H4, H2O, and D2O over wide ranges of temperature and pressure, J. Supercrit. Fluids. 8 (1995) 310-317. doi:10.1016/0896-8446(95)90006-3.

[27] J. Sierra-Pallares, D.L. Marchisio, E. Alonso, M.T. Parra-Santos, F. Castro, M. José Cocero, Quantification of mixing efficiency in turbulent supercritical water hydrothermal reactors, Chem. Eng. Sci. 66 (2011) 1576-1589. doi:10.1016/j.ces.2010.12.039.

[28] J. Rodríguez-Carvajal, Recent advances in magnetic structure determination by neutron powder diffraction, Phys. B Condens. Matter. 192 (1993) 55-69. doi:10.1016/0921-4526(93)90108-I.

[29] E. Lester, P.J. Blood, J.P. Denyer, B.J. Azzopardi, J. Li, M. Poliakoff, Impact of reactor geometry on continuous hydrothermal synthesis mixing, Mater. Res. Innov. 14 (2010) 19-26. doi:10.1179/143307510X12599329343042.

[30] K. Sugioka, K. Ozawa, T. Tsukada, S. Takami, T. Adschiri, K. Sugimoto, et al., Neutron radiography and numerical simulation of mixing behavior in a reactor for supercritical hydrothermal synthesis, AIChE J. 60 (2014) 1168-1175. doi:10.1002/aic.14313. 
[31] T. Aizawa, Y. Masuda, K. Minami, M. Kanakubo, H. Nanjo, R.L. Smith, Direct observation of channeltee mixing of high-temperature and high-pressure water, J. Supercrit. Fluids. 43 (2007) 222-227. doi:10.1016/j.supflu.2007.03.008.

[32] C.Y. Ma, M. Chen, X.Z. Wang, Modelling and simulation of counter-current and confined jet reactors for hydrothermal synthesis of nano-materials, Chem. Eng. Sci. 109 (2014) 26-37. doi:10.1016/j.ces.2014.01.006.

[33] H. Hayashi, A. Ueda, A. Suino, K. Hiro, Y. Hakuta, Hydrothermal synthesis of yttria stabilized ZrO2 nanoparticles in subcritical and supercritical water using a flow reaction system, J. Solid State Chem. 182 (2009) 2985-2990. doi:10.1016/j.jssc.2009.08.013.

[34] K. Sue, M. Suzuki, K. Arai, T. Ohashi, H. Ura, K. Matsui, et al., Size-controlled synthesis of metal oxide nanoparticles with a flow-through supercritical water method, Green Chem. 8 (2006) 634. doi:10.1039/b518291c.

[35] X. Weng, D. Brett, V. Yufit, P. Shearing, N. Brandon, M. Reece, et al., Highly conductive low nickel content nano-composite dense cermets from nano-powders made via a continuous hydrothermal synthesis route, Solid State Ionics. 181 (2010) 827-834. doi:10.1016/j.ssi.2010.04.014.

[36] T. Hirata, E. Asari, M. Kitajima, Infrared and Raman Spectroscopic Studies of ZrO2 Polymorphs Doped with Y2O3 or CeO2, J. Solid State Chem. 110 (1994) 201-207. doi:10.1006/jssc.1994.1160.

[37] X. Weng, D. Brett, V. Yufit, P. Shearing, N. Brandon, M. Reece, et al., Highly conductive low nickel content nano-composite dense cermets from nano-powders made via a continuous hydrothermal synthesis route, Solid State Ionics. 181 (2010) 827-834. doi:10.1016/j.ssi.2010.04.014. 


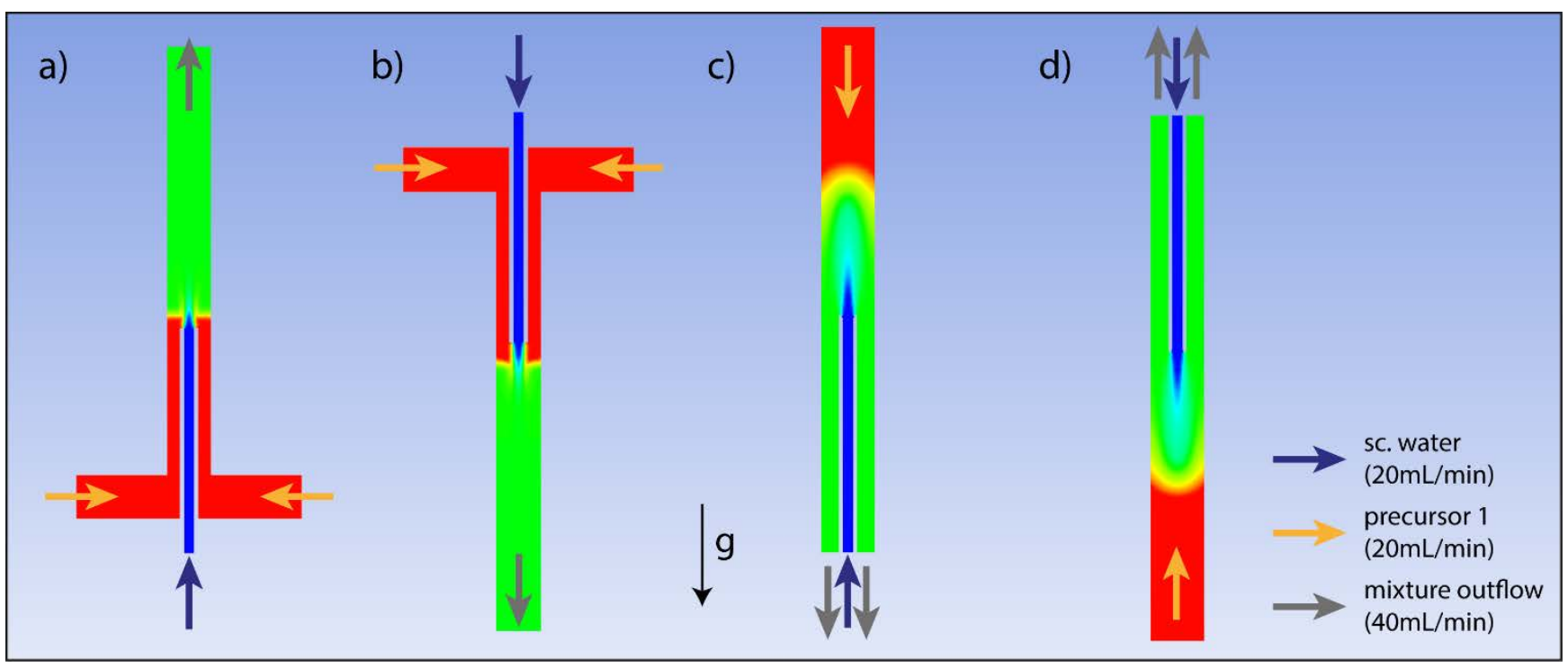

Figure 1: Simulation of (a,b) co- and (c,d) counter-flow geometries of stage 1. The blue arrows indicate the sc.water inlet $\left(20 \mathrm{ml} / \mathrm{min}, 400^{\circ} \mathrm{C}\right)$, the yellow arrows the precursor solution inlet $\left(20 \mathrm{ml} / \mathrm{min}, 20^{\circ} \mathrm{C}\right)$ and the gray arrows the mixture outflow. The color code indicates the precursor tracer concentration: red: feed precursor mixture, blue: feed sc.water, other colors indicate degree of mixture between precursor and sc.water. g indicates the direction of the gravitational force; (a) upward outflow co-flow; (b) downward outflow co-flow; (c) downward outflow counter-flow; (d) upward outflow counter-flow. 


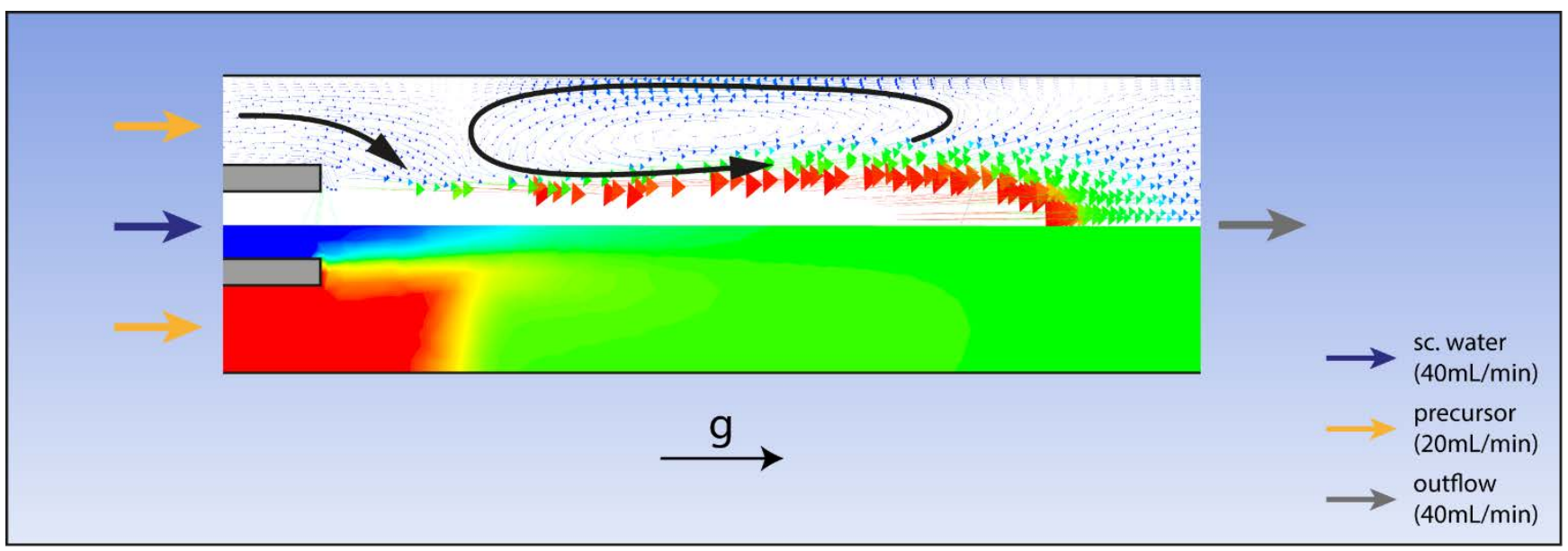

Figure 2: Mixing of stage1, downward outflow co-flow mixer; Top: flow field of the mixer (velocity vectors); bottom: precursor distribution, the color code indicates the precursor tracer concentration: red: feed precursor mixture, blue: feed sc.water, other colors indicate degree of mixture between precursor and sc. water. 

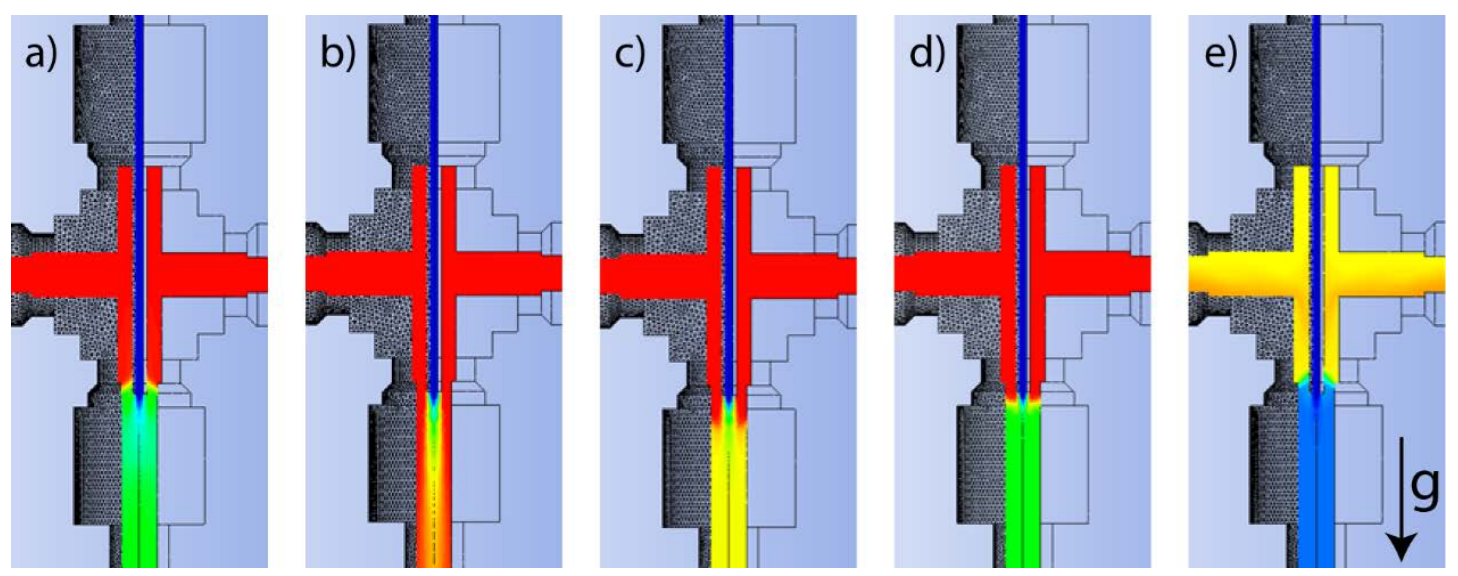

Figure 3: Precursor concentration profiles showing the mixing behavior of stage 1 at different sc. water (SW) and precursor (PC) flow rates, red: high precursor conc., blue: low precursor conc.; (a) SW: 5mL/min, PC: $5 \mathrm{~mL} / \mathrm{min}$, weak backmixing (not reaching the precursor inlet); (b) SW: $5 \mathrm{~mL} / \mathrm{min}$, PC: $55 \mathrm{~mL} / \mathrm{min}$, no complete mixing in the simulated volume; (c) SW: $20 \mathrm{~mL} / \mathrm{min}$, PC: $55 \mathrm{~mL} / \mathrm{min}$, complete mixing in the simulated volume without backmixing; (d) SW: $55 \mathrm{~mL} / \mathrm{min}$, PC: $55 \mathrm{~mL} / \mathrm{min}$, complete mixing in the simulated volume without backmixing; (a) SW: $55 \mathrm{~mL} / \mathrm{min}$, PC: $5 \mathrm{~mL} / \mathrm{min}$, backmixing of sc. water to the precursor inlet. 

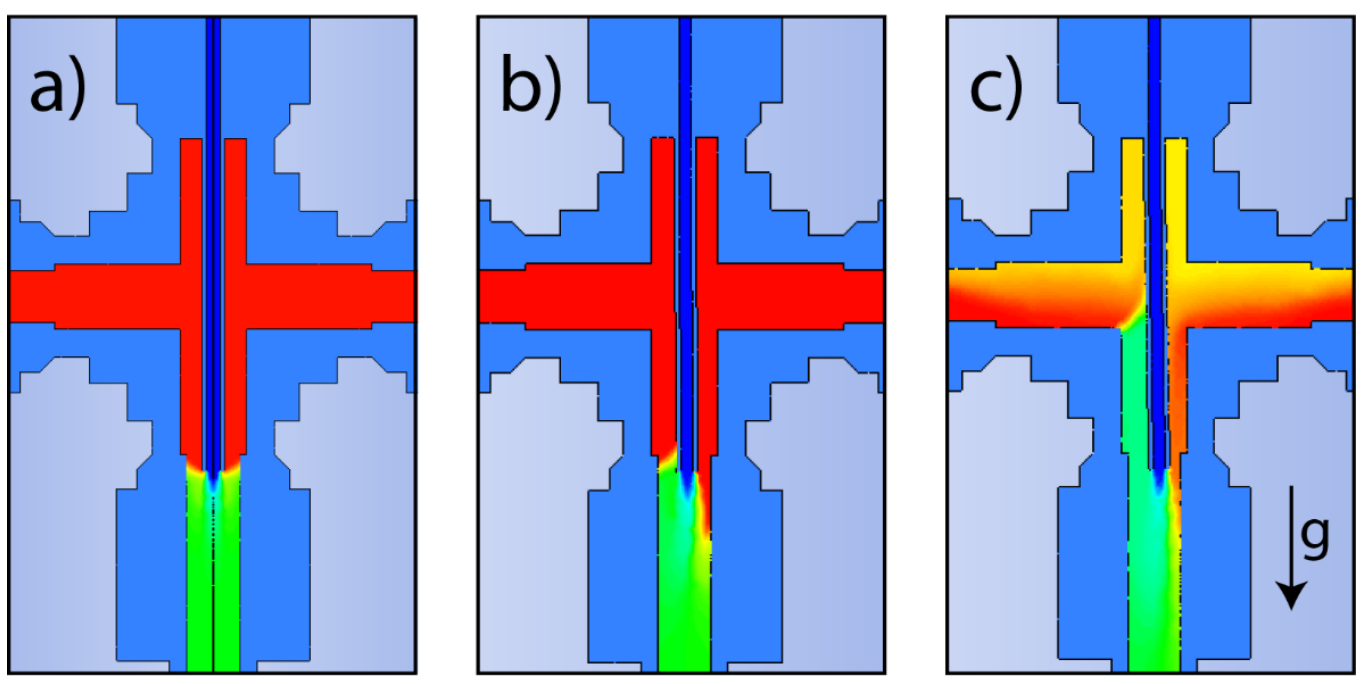

Figure 4: Eccentricity sensitivity of co-flow mixer illustrated by precursor concentration profiles, red: high precursor conc., blue: low precursor conc., a: inner tube perfectly straight, b: inner tube bent $200 \mu \mathrm{m}$ to the right, c: inner tube $400 \mu \mathrm{m}$ bent to the right 


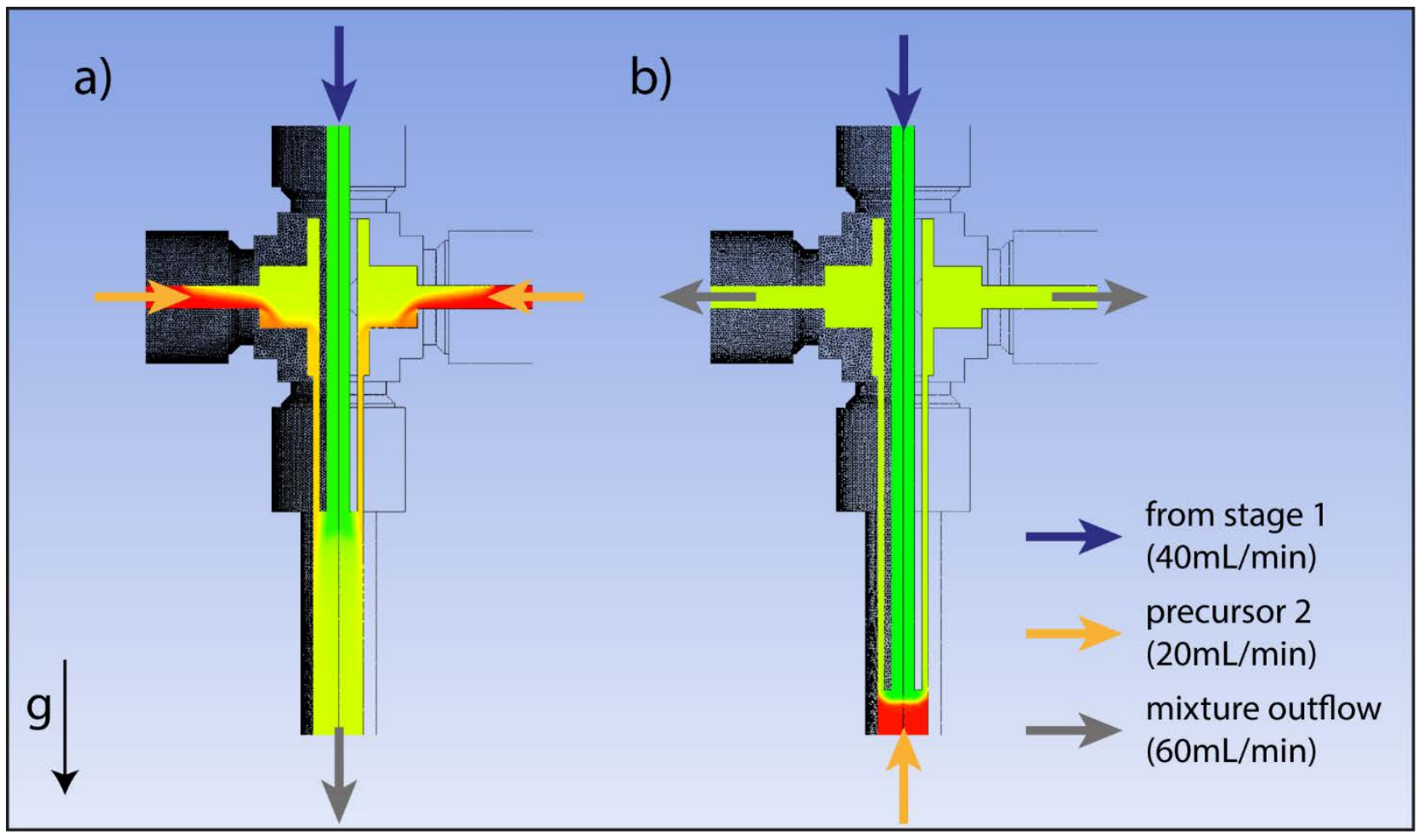

Figure 5: Precursor concentration profiles showing the mixing behavior of co- (a) and counter-flow (b) design for the second mixing stage 


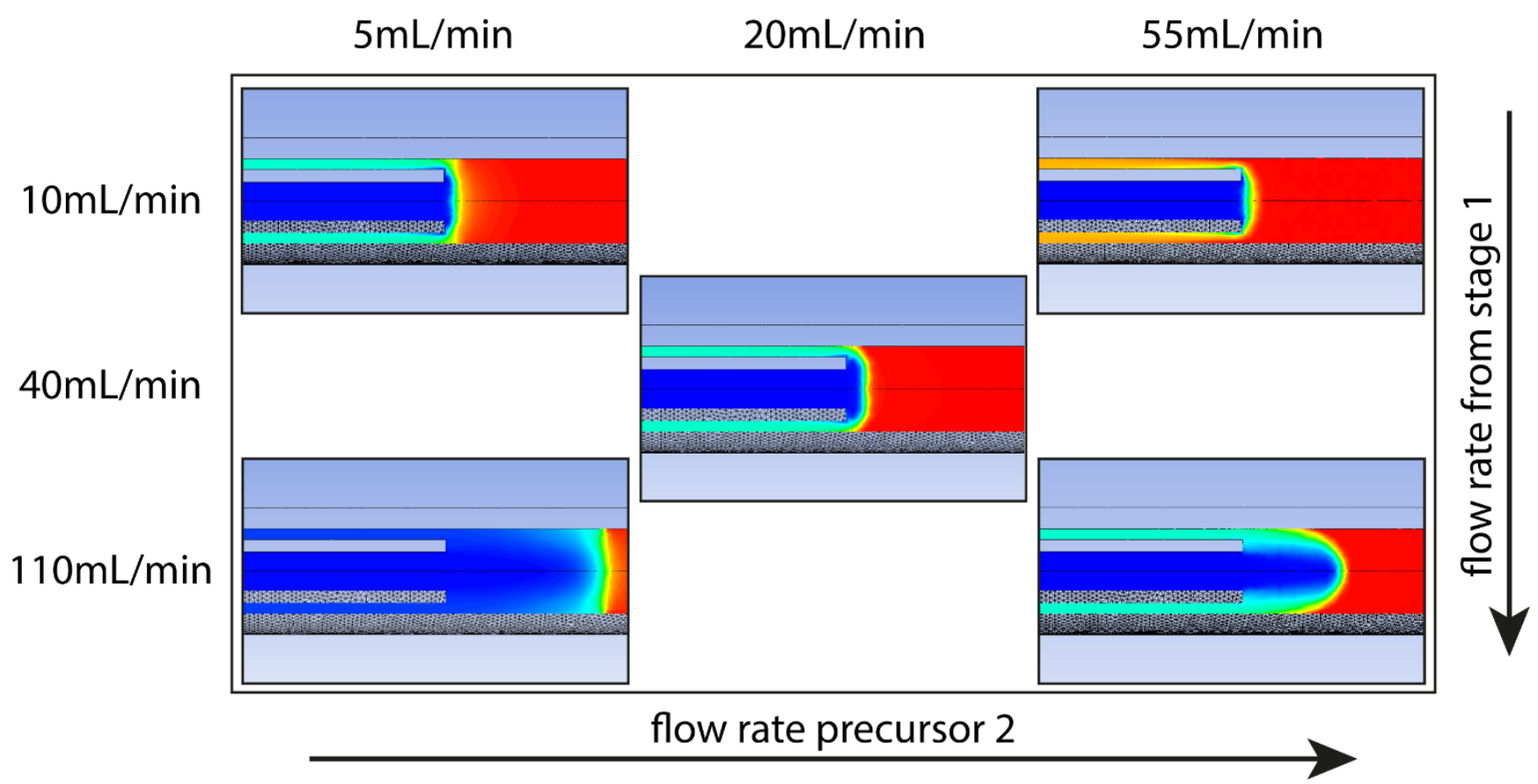

Figure 6: Precursor concentration profiles showing the mixing behavior of stage 2 at different flow rates, red: high precursor conc., blue: low precursor conc. 


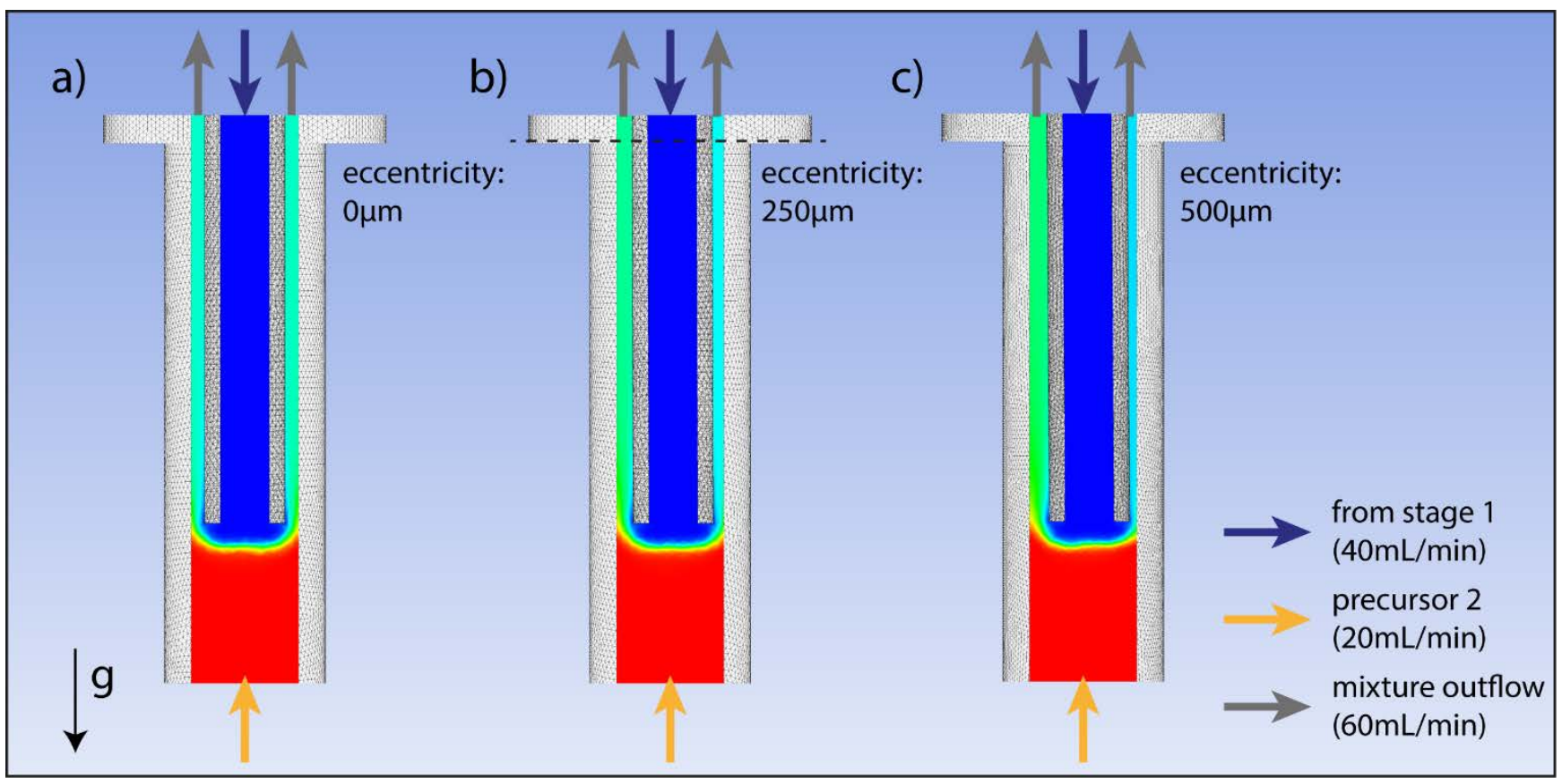

Figure 7: Eccentricity sensitivity of counter-flow mixer (stage 2) illustrated by precursor concentration profiles, red: high precursor conc., blue: low precursor conc., a: $0 \mu \mathrm{m}$ eccentricity, b: $250 \mu \mathrm{m}$ eccentricity, c: $500 \mu \mathrm{m}$ eccentricity; dashed line in b: position 3cm downstream the mixing point 


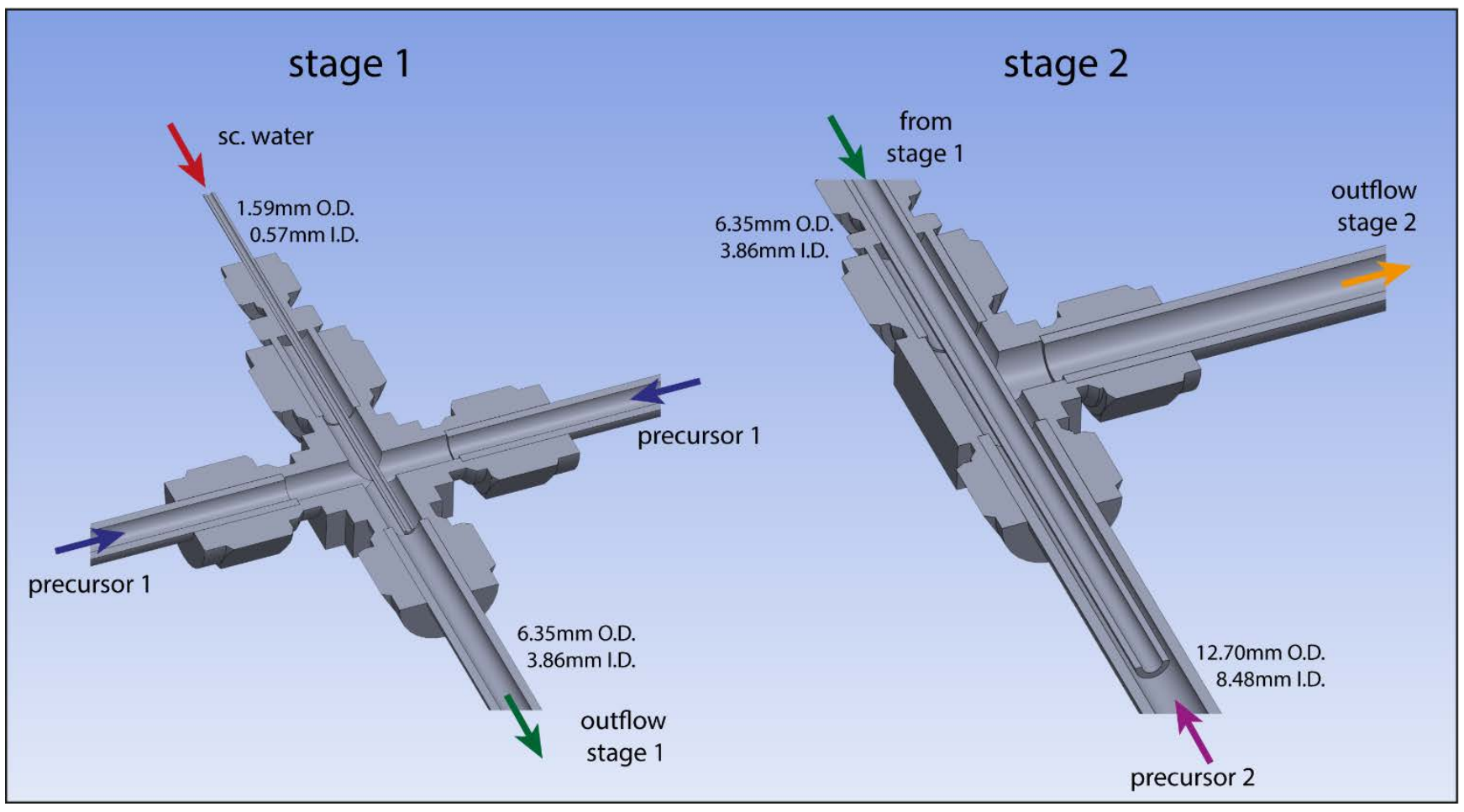

Figure 8: Cross-section of mixing stages $1 \& 2$ 


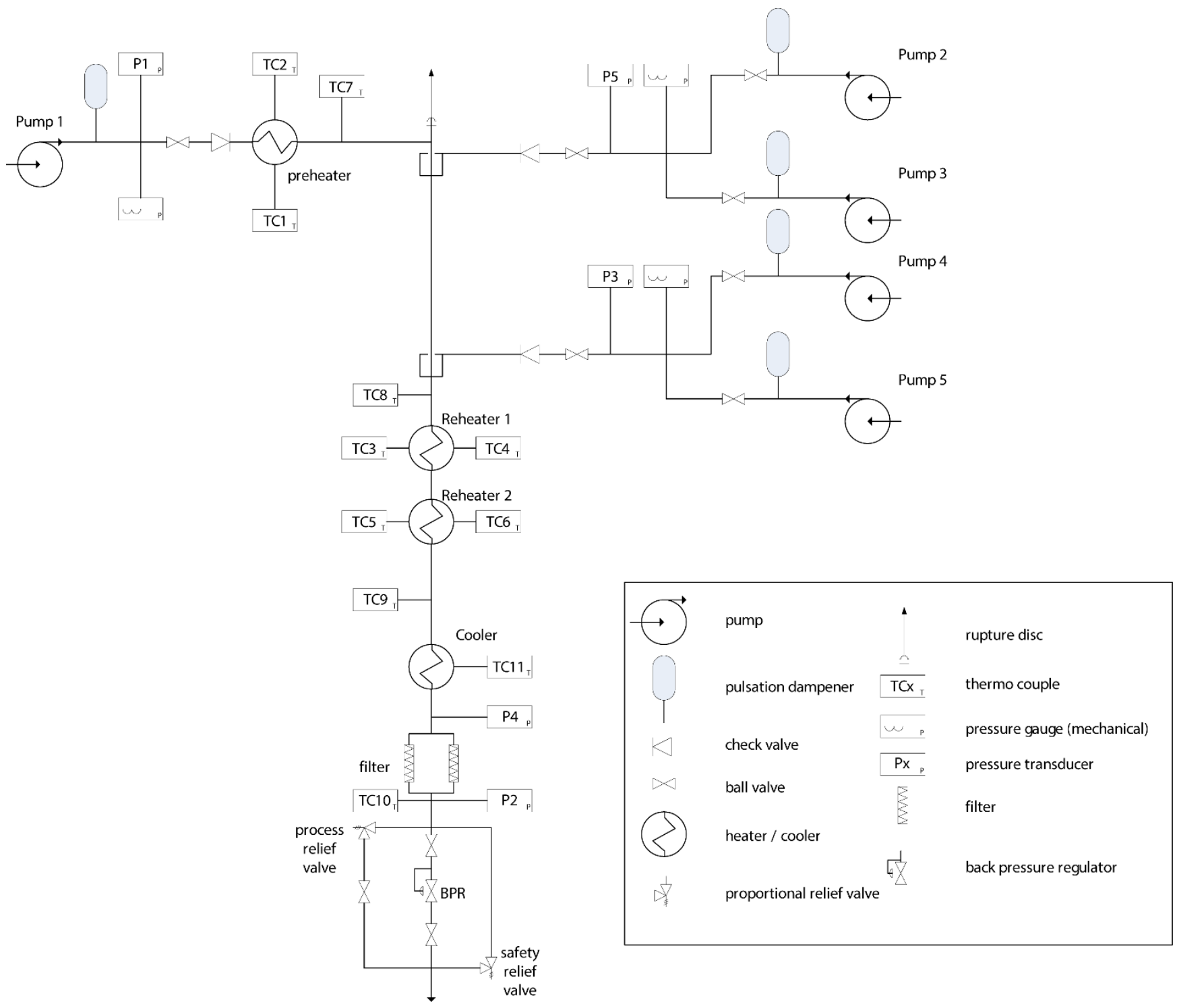

Figure 9: Schematics of the CHFS reactor 

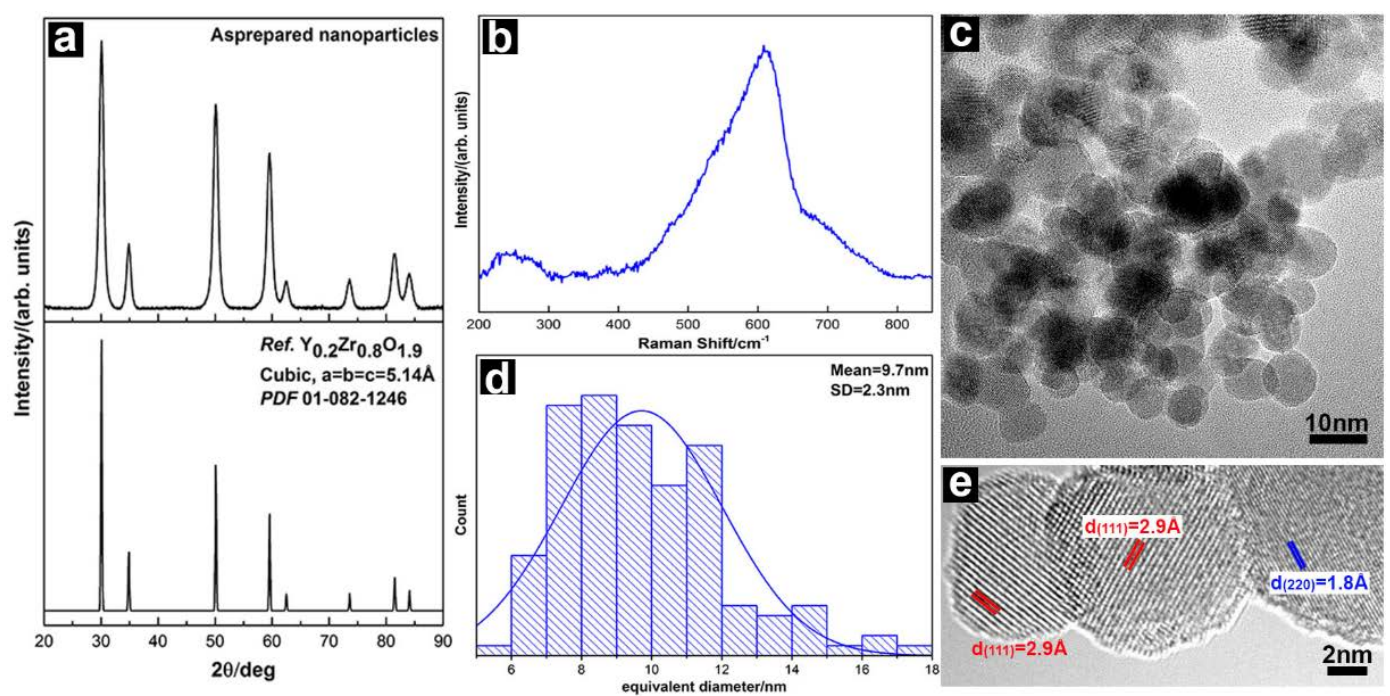

Figure 10: (a) Powder X-ray diffraction pattern of the as-prepared particles and comparison with the reference pattern; (b) Raman spectrum of the as-prepared nanoparticles; (c) Bright field TEM image shows the overview of the as-prepared nanoparticles; (d) Particle size distribution of the YSZ particle diameters measured from TEM images like the one presented in (c). The total number of particles in the distribution is 141. A Gaussian is fitted to the data and the mean particle size and the standard deviation (SD) is calculated based on the Gaussian fit; (e) High resolution TEM image of the nanoparticles; the marked d-spacings correspond well to those of the (111)and (220)-planes in cubic YSZ. 

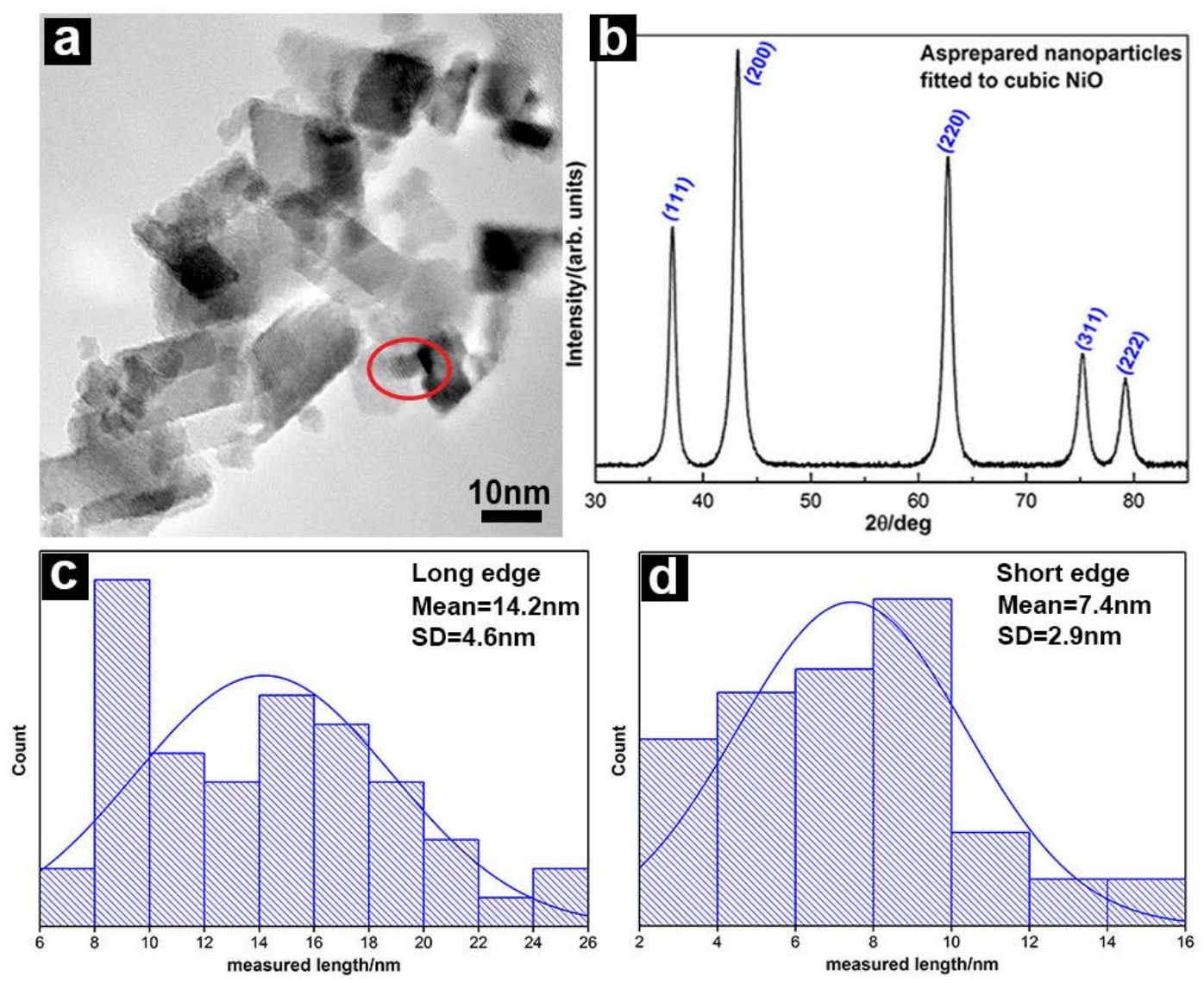

Figure 11: (a) Bright field TEM image shows the general overview of the as-prepared nanoparticles in which Moiré pattern can be observed (see area marked in red); (b) Powder X-ray diffraction pattern, all peaks can be attributed to the separate crystal planes of cubic NiO; (c) Size distribution of the particles' long edge measured from TEM images like the one presented in (a). The total number of particles in the distribution is 51; (d) Size distribution of the particles' short edge. 

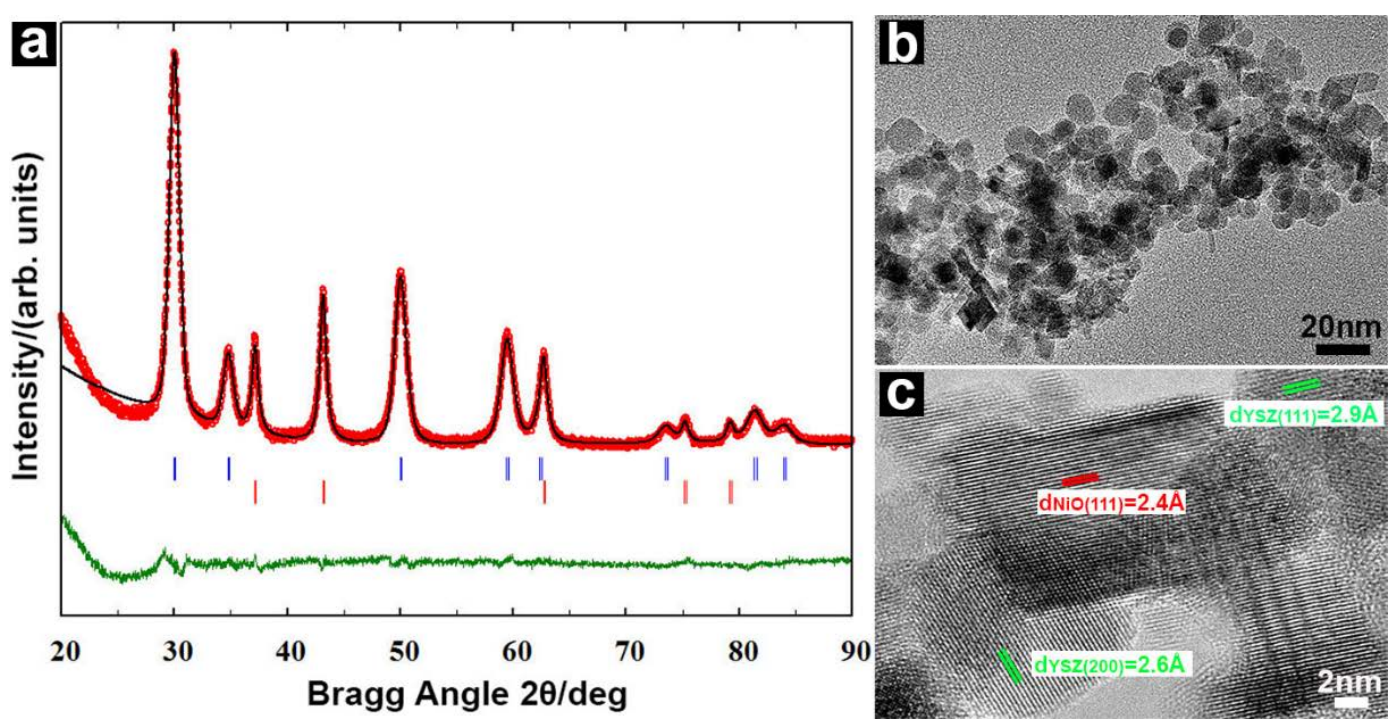

Figure 12: (a) Rietveld refinement of powder X-ray diffraction pattern of the as-prepared mixture (YN1) of nanoparticles; the observed pattern (red circles), the calculated pattern (black line), difference profiles between the observed and the calculated (bottom green line) and the Bragg reflection positions (blue and red vertical bars corresponding to YSZ and NiO respectively); $\mathrm{R}_{\mathrm{p}}$ 8.13, $\mathrm{R}_{\mathrm{wp}}$ 7.09, $\mathrm{R}_{\mathrm{e}} 5.18$ and $\chi^{2}$ 1.88; (b) Bright field TEM image of the overview of the as-prepared nanoparticles; (c) High resolution TEM of the as-prepared nanoparticles; the marked d-spacings correspond well to the lattice spacings in cubic YSZ (green) and NiO (red). 

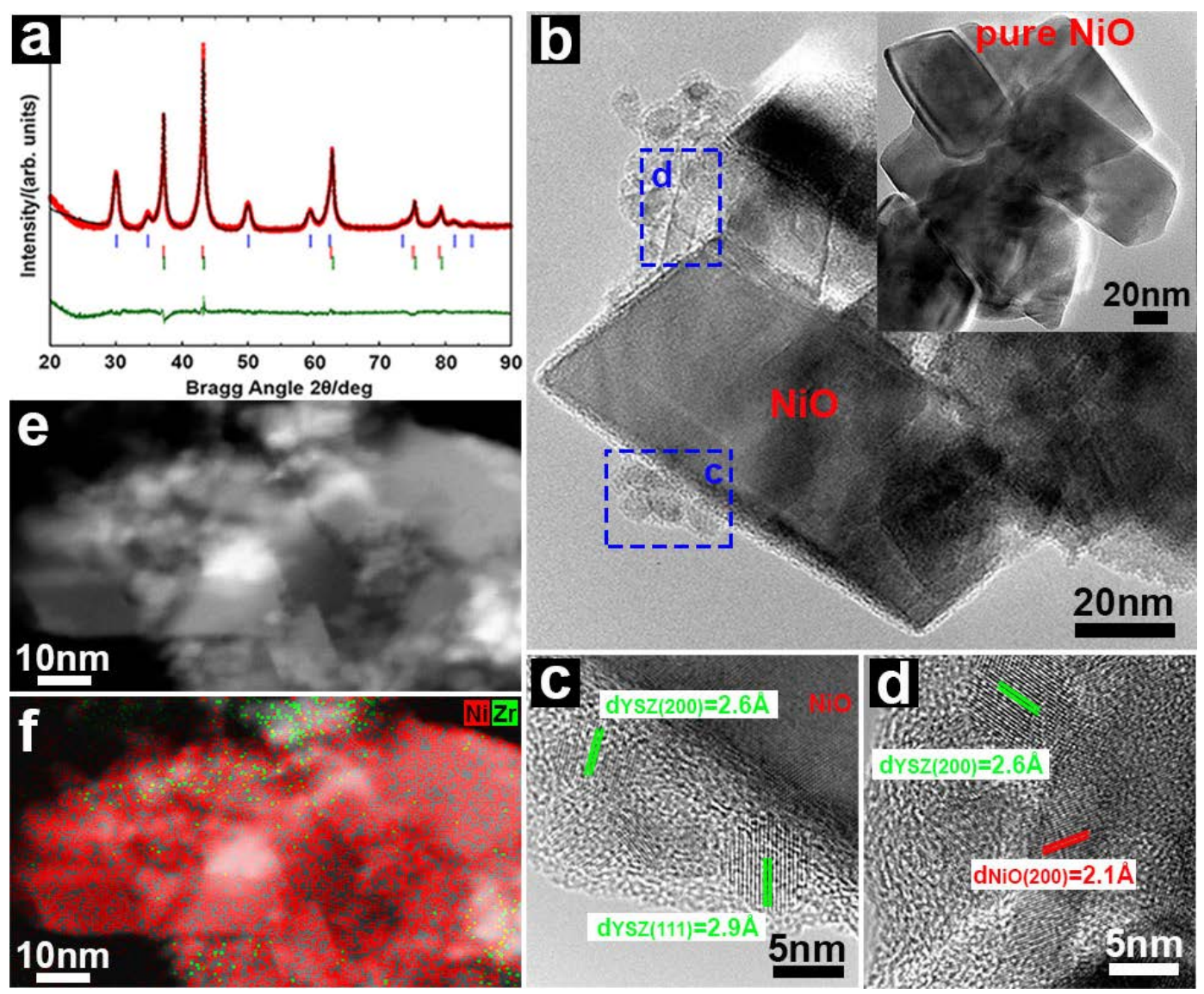

Figure 13: (a) Rietveld refinement of powder X-ray diffraction pattern of the as-prepared mixture (YN2) of nanoparticles; the observed pattern (red circles), the calculated pattern (black line), difference profiles between the observed and the calculated (bottom green line) and the Bragg reflection positions (blue vertical bars corresponding to YSZ; red and green vertical bars corresponding to NiO); $\mathrm{R}_{\mathrm{p}} 9.17, \mathrm{R}_{\mathrm{wp}} 7.69, \mathrm{R}_{\mathrm{e}} 5.18$ and $\chi^{2} 2.20$; (b) Bright field TEM image shows the overview of the as-prepared nanoparticles; insertion is the overview of pure NiO nanoparticles which were sampled before the precursor solution for $8 \mathrm{YSZ}$ was pumped into the CHFS reactor; (c) and (d) are high resolution TEM images of the two representative nano-accumulations highlighted in (b); (e) DF-STEM image of the as-prepared nanoparticles; (f) STEM-EDS element mapping of the as-prepared nanoparticles, $\mathrm{X}$-ray photons from $\mathrm{Ni} \mathrm{K} \alpha$ and $\mathrm{Zr} \mathrm{K} \alpha$ are presented 

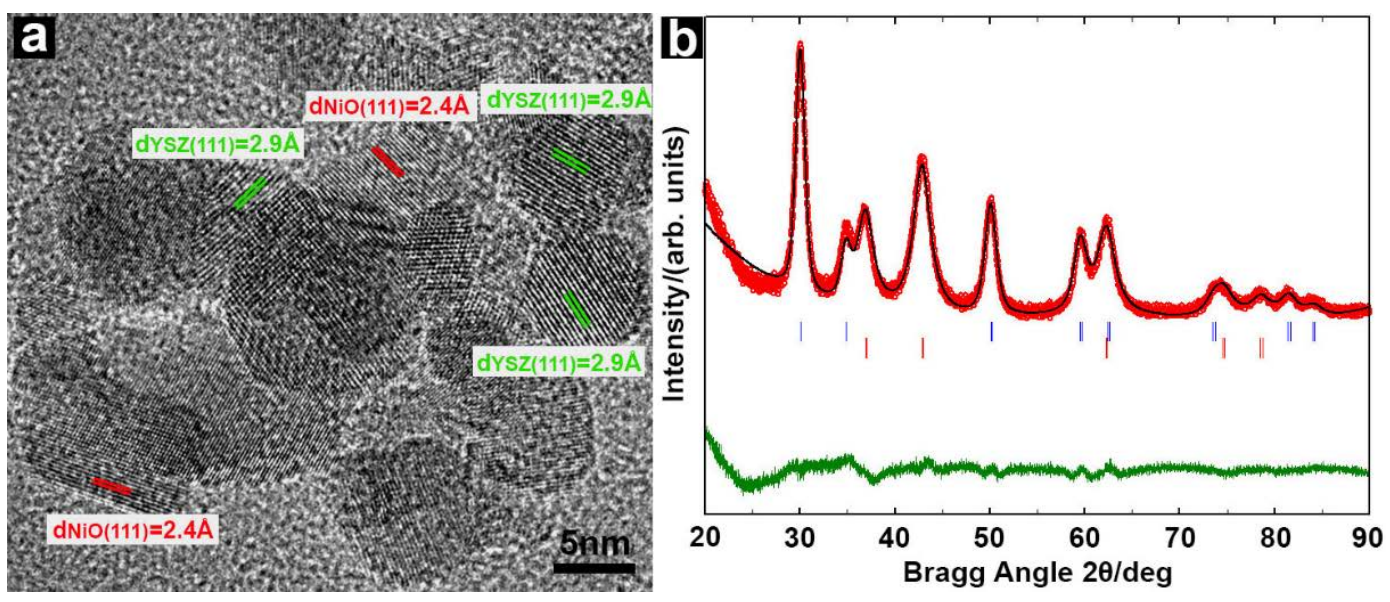

Figure 14: (a) High resolution TEM of the as-prepared nanoparticles; the marked d-spacings correspond well to the lattice spacings in cubic YSZ (green) and NiO (red); (b) Rietveld refinement of powder X-ray diffraction pattern of the as-prepared mixture (YNS) of nanoparticles; the observed pattern (red circles), the calculated pattern (black line), difference profiles between the observed and the calculated (bottom green line) and the Bragg reflection positions (blue vertical and red vertical bars corresponding to cubic YSZ and NiO respectively); $\mathrm{R}_{\mathrm{p}}$ 9.86, $\mathrm{R}_{\mathrm{wp}} 9.55, \mathrm{R}_{\mathrm{e}} 6.19$ and $\chi^{2} 2.38$ 